\title{
Recognition Practices and Employee Performance: Understanding Work Engagement as a Mediating Pathway in Kenyan Context
}

\author{
Idowu Owoeye*, David Kiiru, Jedidah Muli \\ Department of Business Administration, School of Business, Kenyatta University, Nairobi, Kenya \\ Email address: \\ owoeyeidowu@students.ku.ac.ke (I. Owoeye),kiiru.david@ku.ac.ke(D. Kiiru), jedidah.muli@ku.ac.ke(J. Muli) \\ ${ }^{*}$ Corresponding author
}

To cite this article:

Idowu Owoeye, David Kiiru, Jedidah Muli. Recognition Practices and Employee Performance: Understanding Work Engagement as a Mediating Pathway in Kenyan Context. Journal of Human Resource Management. Vol. 8, No. 3, 2020, pp. 163-171.

doi: 10.11648/j.jhrm.201200803.17

Received: March 1, 2020; Accepted: March 16, 2020; Published: July 13, 2020

\begin{abstract}
A number of studies have provided evidence buoying intrinsic rewards as human resource interventions for enhancing performance at individual, functional, and organisational levels. While this evidence abounds mostly in the highincome economies, the direct and indirect pathways through which intrinsic rewards such as recognition practices generate employee's performance lacked empirical and theoretical investigation in the low-income economies. Using survey data from 106 respondents pursuing MBA and $\mathrm{PhD}$ programmes at Kenyatta University, this study investigated the relationship between recognition practices, work engagement, and employees' performance in Kenyan context. The hypotheses of this study were anchored on Social Exchange Theory, and both descriptive and explanatory research designs were employed. Data were obtained from the respondents through self-administered questionnaires and the study instruments were adapted items. The study's instruments were subjected to Principal Component Analysis to determine the validity and reliability of the research instruments, and thereafter the direct hypothesised relationship was determined through linear regression method. The findings from the analysis revealed positive and significant effect of recognition practices on employee performance in Kenyan context. Furthermore, this study used PROCESS macro and found partial mediating effect of work engagement on the relationship between recognition practices and employees' performance. The study offers both theoretical and practical implications which revolve round the need to enhance positive attitudinal outcome (work engagement) that will occasion desired performance at various organisational levels via the design and implementation of employee recognition practices in Kenyan context.
\end{abstract}

Keywords: Recognition Practices, Work Engagement, Employee Performance, Social Exchange Theory

\section{Introduction}

Theoretical assumptions in human resource management literature converged on the premise that performance obtained in an organisation is contingent on the performance of its employees, and therefore such performance is often determined by employees' positive perception of the implemented human resource management interventions. This implies that the performance of people in employment register of a work setting determines the attainment of predetermined organisational goals. Employees are said to be physically, emotionally, and cognitively engaged in their work assignments when organisational events are signaling to them that they are valued and trusted in the organisation $[1 ; 2]$. These events have been identified in HRM literature as HRM systems designed and implemented to enhance the desired organisational performance. A chunk of empirical studies in HRM literature have found positive experience of human resource management systems and performance at both micro and macro level of an organisation [3-5]. Furthermore, what constitutes attitudes and behaviours that will benefit the organisation is said to be hinged on the reality of human resource management interventions against its rhetoric [6]. Studies have therefore provided empirical evidence of positive relationship between human resource management intervention, attitudinal and behavioural 
outcomes, and performance in organisations [7]. Scholars and authors of these profound positive evidences have concentrated attention on HRM interventions for enhancing employee knowledge, skills, and abilities, and as well as motivation via extrinsic rewards, and such evidences are confined to the contexts of the of high-income economies. There is, however, anecdotal evidence of positive relationship of HRM interventions that motivate employee to assume positive work behaviour which will in turn occasion performance at both micro and macro level of an organisation especially in the low-income economies. Employee recognition has therefore been identified as an important HRM intervention that functions as a vector of motivation [8]. It is a significant HRM system instituted to communicate and signal to employees that their organisations are interested in them beyond short term; but rather on long term basis [9]. As posited by [10], recognition practice is an important HRM system that signals to employees that organisation cares about their well-being and is willing to invest in them. While evidence of positive relationship between employee recognition and performance abounds in the high-income countries [9], such evidence is lacking, and in addition the mechanism through which employee recognition generates performance is limited as far as empirical studies in lowincome settings are concerned. Furthermore, organisations adopt employee recognition so as to reinforce the desired behaviours; however, little empirical evidence is available to corroborate this claim [11]. It is against this backdrop that this study investigated the relationship between employee recognition, work engagement, and employee performance in Kenyan context.

\section{Conceptual and Empirical Literature Review}

\subsection{Employee Recognition and Employee Performance}

There is no uniformity as to the conceptualisation of HRM system termed as 'recognition' in a work setting; rather the term has been operationalised in different ways by different researchers. [9, p.330] defines recognition as 'non-monetary reward through which an organisation tangibly signals its appreciation of quality work and achievement'. Recognition of employees at workplace is also conceptualised as "the assignment of personal non-monetary reward to reinforce desired behaviours displayed by an employee, after the behaviours have occurred" [12]. According to [11], employee recognition is defined from the perspective of theories as a reinforcement contingency that has the capacity to shape behaviours and consequently improve performance. In a survey of scientific literature carried out by [8], the concept of employee recognition was coined from ethical, existential, work psychodynamic, and behavioural perspectives, as personal recognition, recognition of work practices, recognition of job dedication, and recognition of results. These typologies of recognition practices have been identified as antecedents of employee attitudinal and behavioural outcomes, and may also have the capacity to enhance performance at both the micro and macro levels of an organisation [8].

A cursory investigation of the relationship between recognition practices, attitudinal, behavioural, and as well as performance outcomes, has shown different evidence of empirical findings. [11], in the study of performance management effectiveness in some private and public organisations in Canada, found positive relationship between employee recognition and performance outcomes. The study of the influence of intrinsic and extrinsic rewards on employee performance in banking sector in Pakistan was investigated by [13], and the findings of the study showed that a positive relationship existed between recognition practice and employee performance. In addition, [14] investigated the relationship between non-monetary rewards, job satisfaction, and job performance in Malaysia, and the findings of the study showed that recognition practices correlated significantly with job performance. [10]'s study on rewards and recognition to engage private banks employees in India found positive correlation between HR outcome (commitment) and recognition practices. In a similar vein, [15] in a field experimental study, found that recognition of employees was attributed to increase in performance outcomes among 312 employees selected to work on threehour data-entry tasks. The evidence of positive relationship between employee recognition and performance outcomes further reinforces the assertion that a strategic approach to recognition provides more engaged and productive employees who will drive organisational performance.

There are, however, empirical studies that have shown negative and insignificant relationship of recognition practices with attitudinal, behavioural, and performance outcomes at different levels of an organisation. [16] found significant correlation between positive recognition and negative emotions among employees when the relationship quality is very low and negative recognition with negative emotions even when the relationship quality is very high. The implication of these findings is that HR managers need to be meticulous when implementing recognition practices because by recognising some employees in a work setting at the expense of others may provoke counterproductive behaviours that may result to adverse organisational performance. Nevertheless, employee recognition has appeared in HRM literature as a vector of motivation that ultimately drives work engagement, and consequently performance outcomes.

\subsection{Work Engagement and Employee Performance}

There is no consensus among scholars and researchers about what constitutes meaning and measurements of engagement [10]. Engagement has been conceptualised in literature as either work or employee engagement $[17 ; 2]$. An engaged employee is the one who is positively engrossed with the assigned work duties and responsibilities towards driving home the desired organisational performance. The array of definitions provided in the literature pointed to the fact that engagement constitutes the deployment of 
employees' physical, emotional and cognitive resources towards the attainment of organisational goals. Engagement refers to the extent to which an individual is attentive, focussed, and absorbed in performing the roles assigned to him or her [1] cited in [18]. In an explanation provided by [19], engagement refers to as a positive, fulfilling, affectivemotivational state of wellbeing that is characterized by vigour, dedication and absorption. This conceptualisation further emphasises on the available resources possessed by employees to getting done appropriately the works assigned to them. The vigour as one of the attributes of engagement indicates employees' willingness to devote time, efforts, and positive energies when performing the job, while dedication refers to emotional form of engagement where employees experience works as meaningful, significant, and challenging and absorption refers to the cognitive form of engagement whereby employees tend to be happily involved and experienced their work as engrossing and something they can devote their full concentration and attention [20].

An attempt to increase employees' engagement level, organisations can expect an increased performance and reduction in employees' probability of departure, and therefore engagement is considered as a psychological and behavioural outcome that leads to better employee performance [21]. In scholarly literature, engagement has been investigated to function either as a predicting or an outcome construct. [22] found in their investigation of worklife balance, job contents, and monetary benefits as drivers of engagement in an organisation. [23], in a research conducted in a New Zealand insurance organisation, found that employee engagement is predicted by leadership behaviours. In the study of [24], situational factors which include training and development, recognition, participatory management, pay and benefits were empirically investigated and found to have positive correlation with employee engagement in engineering and consulting services industries in India. [10], found positive correlation between rewards, recognition practices and engagement in the study of bank employees in India.

Moreover, the concept of engagement has been researched and identified as a route towards accomplishment of an organisational goal. In an empirical study of [17], work engagement was found to fully mediate the relationship between psychological climate and organisational effectiveness in service organisations in India. Similarly, [25] concluded in their study that job performance can be obtained in an organisation if performance management has a positive influence on work engagement. These findings were in consonance with empirical investigation of work engagement as an important antecedent of performance at various levels in perspective of Indian organisations [26-27; 10]. In addition, [6] found work engagement as the antecedent of organisational citizen behaviour and turnover intention in the relationship between human resource management practice and employee behaviour in service sector in UK. The evidence that work engagement creates a brighter future at a service sector in UK [28] corroborated [6]'s study. Drawing from these empirical findings, it is sufficient to say that work engagement constitutes an important attitudinal outcome that can be enhanced via implementation of HRM practices towards attaining the predetermined organisational goals.

\section{Theoretical Framework and Hypotheses Development}

In human resource management literature, researchers have been charged to mobilise theories in the understanding of HRM practices, concept of performance, and the mechanism through which HRM-practices-performance relationship is generated [29]. Researchers have therefore mobilised HRM related theories to support and justify HRMP-performance linkage [30]. Social exchange theory, by [31], is an important theoretical paradigm mobilised in HRM literature to explain employer-employee relationship within the organisation. It is a theory conditioned on the norms of reciprocity within the social relationship [6]. Social exchange theory is used to support argument in HRM literature that employee perception of implemented HRM practices would have a pivotal influence on employee attitudinal and behavioural outcomes which would in turn enhance performance at various organisational levels [32]. That is employees who perceived that HRM practices are investments towards them beyond short-term basis may likely reciprocate in kind by exhibiting positive attitudinal and behavioural outcome that may result in desired organisational outcomes [33]. In the study of [18], social exchange theory was drawn to explain the connection between human resource management practices and work engagement. Similarly, the link between perceived human resource management practices, work engagement, and employee behaviour was rooted in social exchange paradigm [6]. Recognition practices, as one of the HR systems, have been identified as having the capacity to shape behaviour and consequently improve performance [11]. It may therefore be sufficient to say that employees who perceived positive recognition practices at workplace may likely assume positive attitudinal and behavioural outcomes that may result in performance at various organisational levels. Drawing from the preceding explanation and the need to justify direct and indirect HRM practices-performance relationship in a low-income context, this study hypothesised relationships between recognition practices, work engagement, and employee performance in Kenyan context as:

$H_{01}$ : There is no direct significant effect of recognition practices on employee performance in Kenya context.

$\mathrm{H}_{02}$ : Work engagement does not have significant mediating effect on the relationship between recognition practices and employee performance in Kenya context.

The hypothesised relationships in this study are therefore depicted in the conceptual framework as shown in Figure 1. 


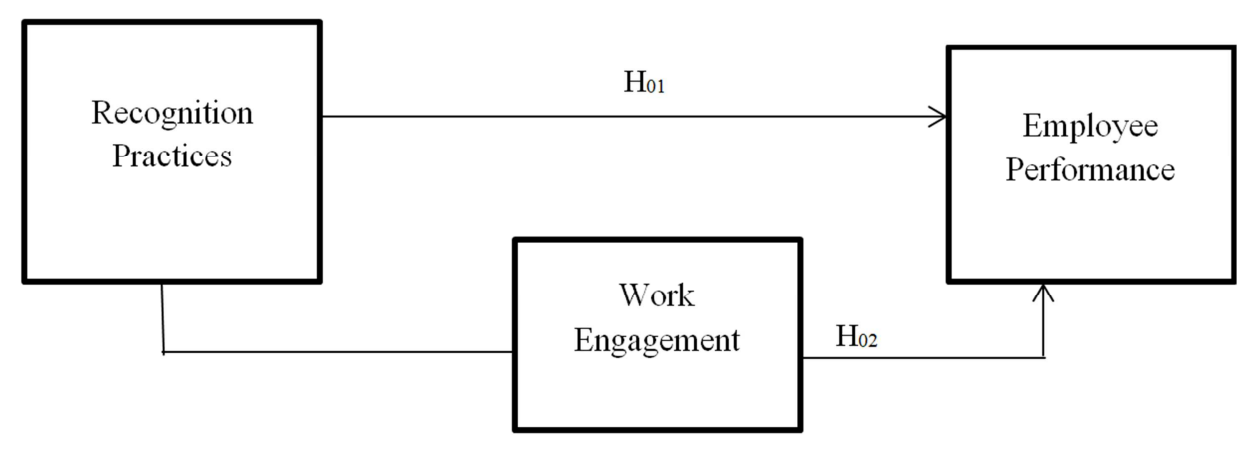

Figure 1 Conceptual Framework.

\section{Methodology}

\subsection{Research Design}

This study adopted descriptive and explanatory research designs, and the study participants were drawn from students pursuing $\mathrm{MBA}$ and $\mathrm{PhD}$ programmes at the School of Business, Kenyatta University. The study relied on data from these participants because consideration is accorded to admitting students into MBA and $\mathrm{PhD}$ programmes with cognate work experience at Kenyatta University. Data obtained from 106 respondents, through self-administered questionnaires, were subjected to both descriptive and inferential analysis using Statistical Package for Social Sciences (SPSS). Out of 106 respondents, 54 per cent were male and 46 per cent were female. The distribution of work experience showed that 26 per cent had 1-5 year work experience, 47 per cent had 6-10 year work experience, 17 per cent had 11-15 year work experience, and 10 per cent had over 16 years work experience.

\subsection{Measures}

The items measuring recognition practices, work engagement, and employee performance were presented in Tables 1 and 2. Recognition practices contained six items adapted from [9]. Work engagement contained nine items adapted from [5], and a modified eleven items measuring employee performance were adapted from [34]. All the items were measured on a 5-point Likert scale ranging from $1=$ strongly disagree to $5=$ strongly agree
Following [5], principal component analysis was performed on 26 items measuring the constructs of this study. Using principal component analysis, the factorability of data is considered suitable when Kaiser-Meyer Olkin (KMO) sampling of adequacy exceed the value of .6, Bartlett's test of sphericity is significant at $\mathrm{p}<0.05$, and correlation matrix (r) showing coefficient 0.3 and above [35]. As shown in Table 1, the KMO exceeded the recommended value of 6 (Recognition practices $=.700$, work engagement $=.781$, employee performance $=.657$ ), and Bartlett's test of sphericity was significant at $\mathrm{p}<0.05$ for all the constructs of the study. Using varimax technique of orthogonal approach for rotation and interpretation, two components solution explaining a total variance of 63.861 with eigenvalue exceeding 1 was revealed for the construct of recognition practices, three components solution explaining 70.614 and 66.835 with the eigenvalue exceeding 1 for the constructs of work engagement and employee performance respectively were also revealed. The components with strong loading of .5 above were considered and this ascertained the construct validity of this study. The strong loading of these components showed that no item was removed before subsequent analysis was performed on the data collected. As also indicated in Table 1, the internal consistency of the constructs of this study was measured and Crombash's alpha values of $.711, .843$, and .819 were found with recognition practices, work engagement, and employee performance respectively. These values exceeded .7 normally used as threshold in research studies [36;31], and this therefore ascertain the reliability of the instruments of this study.

\subsection{Data Analysis}

Table 1. Results of Principal Component Analysis of Variables.

\begin{tabular}{|c|c|c|c|c|}
\hline \multirow{2}{*}{$\mathbf{S} / \mathbf{N}$} & \multirow{2}{*}{$\begin{array}{l}\text { ITEMS } \\
\text { Recognition Practices }\end{array}$} & \multicolumn{3}{|c|}{ Component } \\
\hline & & 1 & 2 & 3 \\
\hline 5. & In my work unit, employees receive written recognition from their supervisors (e.g. memos) & .847 & \multirow{9}{*}{$\begin{array}{l}.862 \\
.793\end{array}$} & \\
\hline 6. & In my work unit, supervisors regularly congratulate employees in recognition of their efforts. & .805 & & \\
\hline 3. & When an employee does good quality work, he or she is showed appreciations by colleagues & .684 & & \\
\hline 4. & $\begin{array}{l}\text { In my work unit, supervisors tangibly appreciate employees in different ways (dinners, restaurants tickets } \\
\text { for sport events or sport, etc.) }\end{array}$ & .634 & & \\
\hline 1. & Employee suggestions are seriously taken into consideration & & & \\
\hline 2. & $\begin{array}{l}\text { In my work unit, employees'suggestions are followed up regularly } \\
\text { Work Engagement }\end{array}$ & & & \\
\hline 8. & I am immersed in my work & .858 & & \\
\hline 7. & I am proud of the work I do & .855 & & \\
\hline 4. & My job inspires me & .738 & & \\
\hline
\end{tabular}




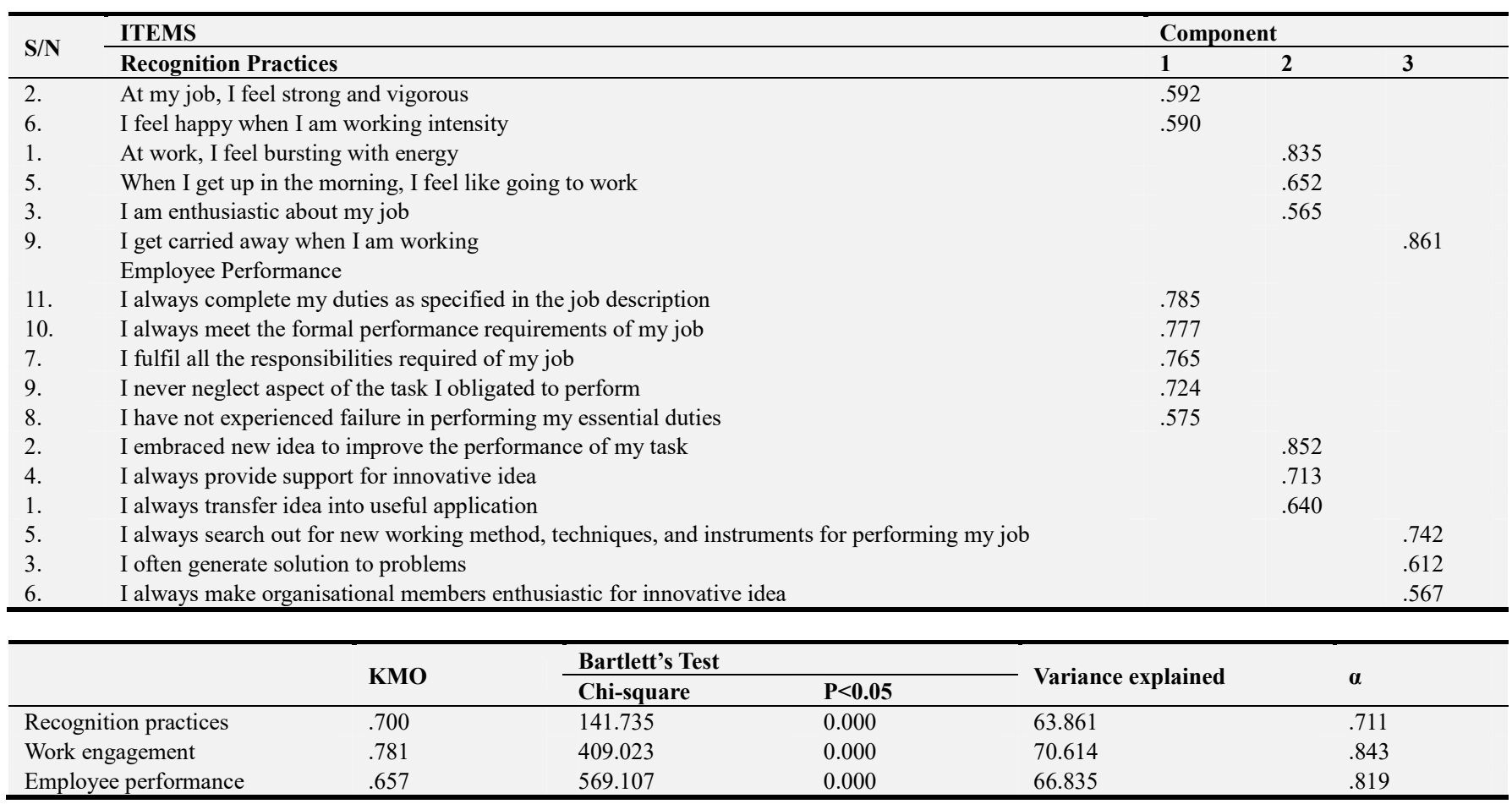

\subsection{Descriptive Analysis}

The aggregate mean and standard deviation scores, as shown in Table 2, stood at 3.2657 and 1.1119 for recognition practices, 3.6834 and 0.9872 for work engagement, and 4.1570 and 0.7943 for employee performance respectively. The aggregate mean score of 3.265 (moderate) on 5-point Likert scale implies that the respondents had a moderate agreement about the existence of recognition practices in their respective organisations, and the standard deviation score of 1.111 indicated a moderate variability of responses. The aggregate mean score of 3.6834 approximates to 4 (agree) on 5-point Likert scale indicated that the respondent showed agreement on the items measuring the construct of work engagement and the standard deviation score of 0.9872 showed low variability of responses among the respondents. The aggregate mean score of 4.1570 (agree) on 5-point Likert showed agreement among the respondents in respect to the items measuring the perceived employee performance, and the standard deviation score of 0.7943 indicated a low variability of responses among the respondents. The low standard deviation scores, as shown in Table 2, explained low variability of responses, and it then indicates that the mean is a true estimate of the population mean.

Table 2 Descriptive Analysis of Variables.

\begin{tabular}{llc}
\hline Variables & Mean & Standard Deviation \\
\hline Recognition Practices & 3.4151 \\
Employee suggestions are seriously taken into consideration & .9347 \\
In my work unit, employees' suggestions are followed up regularly & 3.1981 & .8882 \\
When an employee does good quality work, he or she is showed appreciations by colleagues & 3.4057 & 1.1278 \\
In my work unit, supervisors tangibly appreciate employees in different ways (dinners, restaurants tickets for sport & 3.0566 & 1.3080 \\
events or sport, etc.) & 3.0566 \\
In my work unit, employees receive written recognition from their supervisors (e.g. memos) & 3.4623 \\
In my work unit, supervisors regularly congratulate employees in recognition of their efforts & 3.2657 \\
Aggregate Score: & 1.1312 \\
Work Engagement & 3.1199 \\
At work, I feel bursting with energy & 3.4906 \\
At my job, I feel strong and vigorous & 3.7358 \\
I am enthusiastic about my job & 3.8491 \\
My job inspires me & 3.8113 \\
When I get up in the morning, I feel like going to work & 3.6793 \\
I feel happy when I am working intensity & 3.5943 \\
I am proud of the work I do & 3.9245 \\
I am immersed in my work & 3.9391 \\
I get carried away when I am working & .8484 \\
Aggregate Score: & 3.0964 \\
Employee Performance & 3.2642 \\
I always complete my duties as specified in the job description & 3.6834 \\
\hline
\end{tabular}




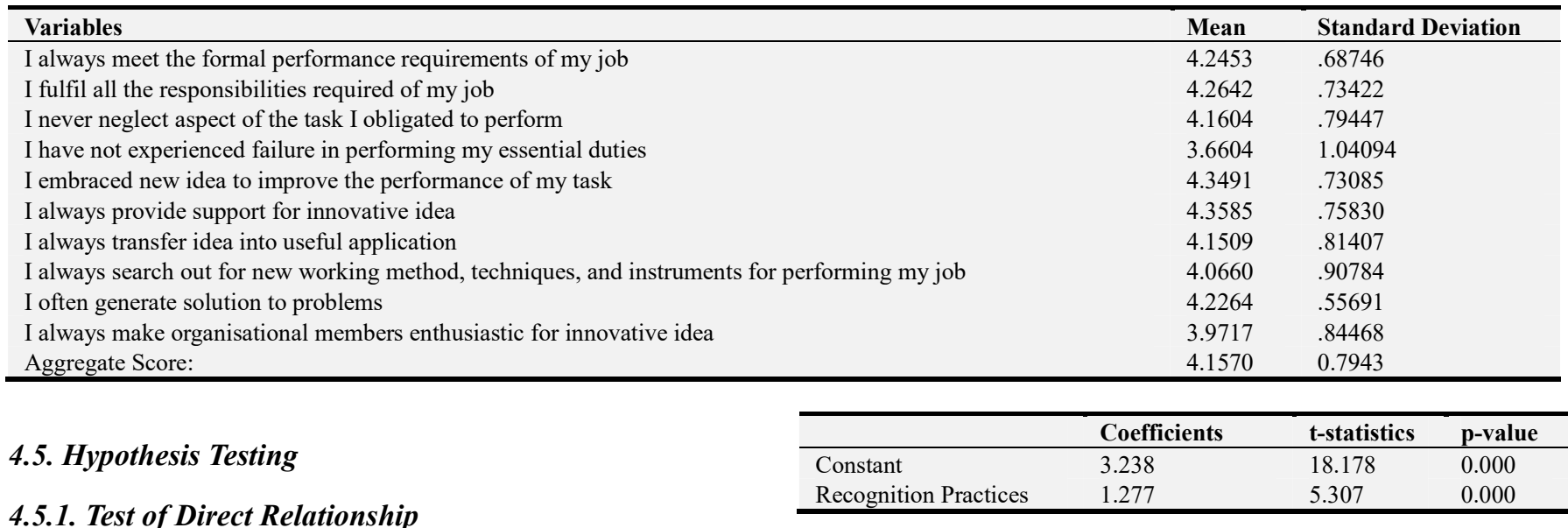

Simple regression analysis was performed to establish the direct relationship between recognition practices and employee performance. As shown in Table 3, the R-square of 0.213 indicated that 21.3 per cent of the variation in the dependent variable (employee performance) was explained by the independent variable (Recognition practices), and the other 78.7 per cent would be explained by variables not mentioned in this study. The F-value of 28.167 was statistically significant at $\mathrm{p}=$ 0.000 , and this indicated that the regression model fitted the data. The t-statistics of 5.307 was statistically significant at $p=0.000$ $(p<0.05)$, and this indicated that a null hypothesis of no significant effect of the relationship between recognition practices and employee performance was rejected. The regression coefficient $(\beta) 1.277$ indicated a positive relationship and this means that one unit increase in recognition practices will lead to 1.227 increases in employee performance.

Table 3 Regression Results for Direct Relationship.

\begin{tabular}{lll}
\hline Goodness of fit & Test Statistics & p-value \\
\hline $\mathrm{R}$ & 0.462 & \\
R-squared & 0.213 & \\
Adjusted R-squared & 0.206 & \\
F-value & 28.167 & 0.000 \\
\hline
\end{tabular}

Dependent Construct $=$ Employee Performance

Table 4 Summary of Regression Results for Mediating Effect.

\begin{tabular}{lllll}
\hline Parameter & Step 1 Total Effect & Step 2 Direct Effect & Step 3 Indirect Effect & Test \\
\hline $\mathrm{R}$ & 0.4116 & 0.5619 & 0.3126 & \\
$\mathrm{R}^{2}$ & 0.2131 & 0.3157 & 0.0977 & \\
F-value & 28.1668 & 23.7629 & 11.2632 & $0.2768-0.2136=0.0632$ \\
Sig $(0.05)$ & 0.000 & 0.000 & 0.011 & $0.2581 * 0.2449=0.0632$ \\
Rec. Pract. & 0.2768 & 0.2136 & 0.2581 & effect \\
Wrk Eng. & - & 0.2449 & 0.0632 & \\
\hline
\end{tabular}

Note: Coefficient is significant at 5 per cent, $\mathrm{p}<0.05$

\section{Discussion}

The results of this study showed that the direct relationship between recognition practices and employee performance was positive and significant, and therefore, are in consonance with the findings of previous empirical studies that found significant and positive correlation between recognition practices and performance at the
Note: $p$ is statistically significant at $5 \%$ level of sig.

\subsubsection{Test of Indirect Relationship}

The hypothesis of indirect relationship in this study was tested using PROCESS macro version 3 developed by [37]. Following the three-variable model for testing mediation effect by [38], one of the decision criteria for mediation effect states that if the difference between the coefficient of the predicting variable in the total effect and the coefficient of the predicting variable in the direct effect is equal to the interactional effect of the coefficients of the mediating variable in both direct effect and indirect effect, then a partial mediating effect has occurred. As shown in Table 4, the difference of the coefficients of predicting variable (Recognition practices) in both the total and direct effect $(0.2768-0.2136=0.0632)$ was equal to the interactional effect of both coefficients of mediating variable (Work engagement $)$ in direct and indirect effect $(0.2581 * 0.2449=$ 0.0632). The coefficient ( $\beta$ ) 0.0632 was statistically significant and the null hypothesis of no mediating effect was rejected. Therefore, the relationship between recognition practices and employee performance was partially mediated by work engagement. 
that work engagement can act as an outcome of HRM practices and also function as antecedent of performance at various organisational levels. This therefore justifies the tenet of social exchange theory (SET) and also in conformity with findings of previous studies with evidence of positive relationship between recognition practices, employee attitudinal and behavioural, and as well as performance outcomes $[8 ; 10]$. Work engagement, via the findings of this study, therefore provides a route through which recognition practices enhance employee performance.

\section{Conclusion}

The findings of this study have some implications that characterised the study's strength and, also provide directions for shaping researchers' interests on further empirical inquiry on the constructs of recognition practices and performance at both micro and macro levels of an organisation.

\subsection{Theoretical Implications}

The findings of this study contribute to HRM literature in the following ways. Firstly, as a response to call for research studies on the outcome and antecedent of work engagement in HRM literature $[39 ; 40]$, the empirical findings of work engagement in this study contribute to the unearthing of the 'black box' as a mechanism via which HRM practices generate performance outcomes. Secondly, anecdotal and little attention has been paid to research studies on the relationship between recognition practices and employee performance and their mediating pathway mostly in the low-income countries [41;42; 43], the strength of this study lies in the findings of positive and significant effect of recognition practices, work engagement, and employee performance in the context of Kenya as a low-income country. Researchers have been enjoined to mobilised theories in an attempt to conceptualise HRM practices, performance, and explain the mechanisms via which HRM practices generate performance outcomes, and the dearth of mobilisation of theories has characterised HRM literature in the non-western countries. The strength of this study, therefore, lies in the mobilisation of social exchange theory in anchoring its objectives and hypothesised relationships.

\subsection{Practical Implications}

The findings of this study have practical implications that can be employed to enhance effective utilisation of human capital in a low-income country such as Kenya. Firstly, the findings of this study clearly demonstrate to the management of organisations in Kenya that monetary rewards practices are not only HRM systems for inducing positive attitudinal and behavioural outcomes that can in turn lead to performance, but also important non-monetary reward practices such as employee recognition. The findings of this study clearly provide a platform for managers of different organisational settings that understanding employee attitudes and its enhancement by designing and implementing important HRM practices would likely endear the desired organisational performance. An important aspect of HRM practices that do not heighten organisational expenses is the implementation of non-monetary practices such as employee recognition; therefore the findings of positive relationship between recognition practices, work engagement, and performance are eye-opener to management of Kenyan organisations to obtain desired performance without recourse to incurring unnecessary expenses.

\subsection{Limitations and Direction for Future Research Studies}

This current study has some limitations that may warrant further empirical inquiries. Firstly, the coefficient of determination in the model summary of this study was significantly less than thirty per cent. This then implies that there are other variables of HRM practices that account for seventy per cent explanation of the construct of employee performance. Future research studies on HRM practices and performance relationship in Kenyan context should beam more light on other components of HRM systems that can occasion performance. The current study is cross-sectional and the evidence of positive correlation was found between recognition practices, work engagement, and employee performance, however, the findings of positive correlation cannot be akin to causal relationship. Subsequent research studies, therefore, should endeavour to find a causal relationship between recognition practices and performance using longitudinal study.

\section{References}

[1] Saks, A. M. (2006). Antecedents and consequences of employee engagement. Journal of managerial psychology, 21 (7), 600-619.

[2] Rich, B. L., Lepine, J. A., \& Crawford, E. R. (2010). Job engagement: Antecedents and effects on job performance. Academy of management journal, 53 (3), 617-635.

[3] Boselie, P. (2010). High performance work practices in the health care sector: a Dutch case study. International Journal of Manpower, 31 (1), 42-58.

[4] Mostafa, A. M. S. (2016). High-performance HR practices, work stress and quit intentions in the public health sector: Does person-organization fit matter?. Public Management Review, 18 (8), 1218-1237.

[5] Karatepe, O. M., \& Olugbade, O. A. (2016). The mediating role of work engagement in the relationship between highperformance work practices and job outcomes of employees in Nigeria. International Journal of Contemporary Hospitality Management, 28 (10), 2350-2371.

[6] Alfes, K., Truss, C., Soane, E. C., Rees, C., \& Gatenby, M. (2013). The relationship between line manager behavior, perceived HRM practices, and individual performance: Examining the mediating role of engagement. Human resource management, 52 (6), 839-859.

[7] Karatepe, O. M., \& Vatankhah, S. (2015). High-performance work practices, career satisfaction, and service recovery performance: a study of flight attendants. Tourism Review, 70 (1), 56-71. 
[8] Brun, J. P., \& Dugas, N. (2008). An analysis of employee recognition: Perspectives on human resources practices. The International Journal of Human Resource Management, 19 (4), 716-730.

[9] Paré, G., \& Tremblay, M. (2007). The influence of highinvolvement human resources practices, procedural justice, organizational commitment, and citizenship behaviors on information technology professionals' turnover intentions. Group \& Organization Management, 32 (3), 326-357.

[10] Ghosh, P., Rai, A., Chauhan, R., Baranwal, G., \& Srivastava, D. (2016). Rewards and recognition to engage private bank employees: Exploring the "obligation dimension". Management Research Review, 39 (12), 1738-1751.

[11] Haines III, V. Y., \& St-Onge, S. (2012). Performance management effectiveness: practices or context?. The International Journal of Human Resource Management, 23 (6), 1158.

[12] Long, R. J., \& Shields, J. L. (2010). From pay to praise? Noncash employee recognition in Canadian and Australian firms. The International Journal of Human Resource Management, 21 (8), 1145-1172.

[13] Khan, I., Shahid, M., Nawab, S., \& Wali, S. S. (2013). Influence of intrinsic and extrinsic rewards on employee performance: The banking sector of Pakistan. Academic Research International, 4 (1), 282.

[14] Abdullah, A. A., \& Wan, H. L. (2013). Relationships of nonmonetary incentives, job satisfaction and employee job performance. International Review of Management and Business Research, 2 (4), 1085.

[15] Bradler, C., Dur, R., Neckermann, S., \& Non, A. (2016). Employee recognition and performance: A field experiment. Management Science, 62 (11), 3085-3099.

[16] Feys, M., Anseel, F., \& Wille, B. (2013). Responses to coworkers receiving recognition at work. Journal of Managerial Psychology, 28, 492-510.

[17] Kataria, A., Rastogi, R., \& Garg, P. (2013). Organizational effectiveness as a function of employee engagement. South Asian Journal of Management, 20 (4), 56.

[18] Presbitero, A. (2017). How do changes in human resource management practices influence employee engagement? A longitudinal study in a hotel chain in the Philippines. Journal of Human Resources in Hospitality \& Tourism, 16 (1), 56-70.

[19] Schaufeli, W. B., Salanova, M., González-Romá, V., \& Bakker, A. B. (2002). The measurement of engagement and burnout: A two sample confirmatory factor analytic approach. Journal of Happiness studies, 3 (1), 71-92.

[20] Bakker, A. B., Albrecht, S. L., \& Leiter, M. P. (2011). Key questions regarding work engagement. European journal of work and organizational psychology, 20 (1), 4-28.

[21] Rawal, S. (2015). Predictors of employee engagement in public \& private insurance companies. Indian Journal of Industrial Relations, 285-299.

[22] Joshi, R. J., \& Sodhi, J. S. (2011). Drivers of employee engagement in Indian organizations. Indian Journal of Industrial Relations, 162-182.

[23] Xu, J., \& Cooper Thomas, H. (2011). How can leaders achieve high employee engagement? Leadership \& Organization
Development Journal, 32 (4), 399-416.

[24] Mishra, B., Sharma, B. R., \& Bhaskar, A. U. (2015). Predictors of employee engagement: the case of an Indian PSU. The Indian Journal of Industrial Relations, 469-478.

[25] Noronha, S. F., Aquinas, P. G., \& Manezes, A. D. (2018). Is Job Performance Better Attributable To Performance Management System Through Work Engagement? Indian Journal of Commerce and Management Studies, 9 (1), 1-6.

[26] Anitha, J. (2014). Determinants of employee engagement and their impact on employee performance. International journal of productivity and performance management, 63 (3), 308.

[27] Bedarkar, M., \& Pandita, D. (2014). A study on the drivers of employee engagement impacting employee performance. Procedia-Social and Behavioral Sciences, 133, 106-115.

[28] Cattermole, G., Johnson, J., \& Jackson, D. (2014). Employee engagement creates a brighter economic future at Jupiter Hotels. Strategic HR Review, 13 (2), 81-85.

[29] Guest, D. E. (1997). Human resource management and performance: a review and research agenda. International journal of human resource management, 8 (3), 263-276.

[30] Owoeye, I., Kaumbulu, A, K., \& Alago, D. (2019). Innovative Employment Practices and Employees' Performance: Understanding Mediating Effect of Self-efficacy in the Context of Collectivist Economy. Journal of Environmental Sustainability Advancement Research, 5, 96-102.

[31] Blau, P. M. (1964). Social exchange theory. Retrieved September, 3 (2007), 62. 1175.

[32] Owoeye, I., \& Muathe, S. M. (2018). Competence-Enhancing Interventions and Organisational Performance: A Theoretical Review. Journal of Human Resource Management, 6 (2), 6777, doi: 10.11648/j.jhrm.20180602.14.

[33] Snape, E., \& Redman, T. (2010). HRM practices, organizational citizenship behaviour, and performance: A multi - level analysis. Journal of management studies, 47 (7), 1219-1247.

[34] Janssen, O., \& Van Yperen, N. W. (2004). Employees' goal orientations, the quality of leader-member exchange, and the outcomes of job performance and job satisfaction. Academy of management journal, 47 (3), 368-384.

[35] Pallant, J. (2005). SPSS Statistical Manual, $2^{\text {nd }}$ ed., Allen \& Unwin, Crows Nest.

[36] Muli, J. V., Muathe, S., \& Muchiri, M. (2014). Human Resource Work-Family Support Services and Employees' Performance within the Banking Industry in Nairobi County, Kenya. International Journal of Humanities and Social Science, 4 (7), 158-170.

[37] Hayes, A. F. (2018). The PROCESS macro for SPSS and SAS. Introduction to mediation, moderation, and conditional PROCESS analysis, second edition: A regression-based approach.

[38] MacKinnon, D. P., Lockwood, C. M., Hoffman, J. M., West, S. G., \& Sheets, V. (2002). A comparison of methods to test mediation and other intervening variable effects. Psychological methods, 7 (1), 83.

[39] Lee, J., \& Ok, C. M. (2016). Hotel employee work engagement and its consequences. Journal of Hospitality Marketing \& Management, 25 (2), 133-166. 
[40] Karatepe, O. M. (2014). Hope, work engagement, and organizationally valued performance outcomes: an empirical study in the hotel industry. Journal of Hospitality Marketing \& Management, 23 (6), 678-698.

[41] Ndungu, D. N. (2017). The Effects of Rewards and Recognition on Employee Performance in Public Educational Institutions: A Case of Kenyatta University, Kenya. Global Journal of Management And Business Research.
[42] Njanja, L. W., Maina, R. N., Kibet, L. K., \& Njagi, K. (2013). Effect of reward on employee performance: A case of Kenya Power and Lighting Company Ltd., Nakuru, Kenya.

[43] Muogbo, U. S. (2013). The impact of employee motivation on organisational performance (a study of some selected firms in Anambra State Nigeria). The international journal of engineering and science, 2 (7), 70-80. 